\title{
Myeloproliferative neoplasm with ETV6-ABL1 fusion: a case report and literature review
}

\author{
Katya Gancheva ${ }^{1}$, Andres Virchis ${ }^{2}$, Julie Howard-Reeves ${ }^{3}$, Nick CP Cross $^{4}$, Diana Brazma ${ }^{3}$, Colin Grace ${ }^{1}$, \\ Paul Kotzampaltiris ${ }^{3}$, Fedra Partheniou ${ }^{3}$ and Elisabeth Nacheva ${ }^{1,3^{*}}$
}

\begin{abstract}
ETV6-ABL1 is a rare gene fusion with oncogenic properties, reported so far in 28 patients presenting a variety of haematological malignancies associated with clinical outcome, including chronic myeloid leukaemia (CML), acute myeloid leukaemia (AML), acute lymphoblastic leukaemia (ALL) and chronic myeloproliferative neoplasm (CMPN). Here we report on a 46-year-old female who presented with Philadelphia negative CML, positive for the ETV6-ABL1 fusion. Whole genome screening carried out with oligonucleotide arrays showed a subtle loss at 12p13 and cryptic imbalances within the 9q34.3 region in a highly unstable genome. FISH mapping with custom BAC probes identified two breakpoints $5 \mathrm{Mb}$ apart within the $9 \mathrm{q} 34$ region, together with a break at 12p13. While FISH with commercial BCRABL1 probes failed to detect any ABL1 changes, the ETV6 break-apart probe conclusively identified the ETV6-ABL1 fusion thus determining the probe's role as the primary diagnostic FISH test for this chimeric oncogene. In addition, we confirm the association of the ETV6-ABL1 fusion with imatinib resistance reported so far in three other patients, while recording excellent response to the $2^{\text {nd }}$ generation tyrosine kinase inhibitor (TKI) nilotinib. In summary, we highlight the value of ETV6 FISH as a diagnostic test and the therapy resistance of ETV6-ABL1 positive disorders to imatinib.
\end{abstract}

Keywords: ETV6-ABL1, Atypical CML, Nilotinib, Resistance to imatinib

\section{Introduction}

CML is one of the most extensively studied human malignancies and was the first example of a disease, where the underlying molecular basis was a consistent chromosomal abnormality, the Philadelphia chromosome $(\mathrm{Ph})$, that is the product of a balanced reciprocal translocation involving chromosomes 9 and 22. Over 95\% of CML patients are found to carry the $\mathrm{t}(9 ; 22)(\mathrm{q} 34 ; \mathrm{q} 11)$ and the resultant $B C R / A B L 1$ fusion gene as postulated by WHO classification (2008) [1]. Six other genes in addition to $B C R$ can form a fusion product with $A B L 1$. The chimeric proteins contain the kinase domain of ABL1 and are composed of the $\mathrm{N}$-terminal part of the partner protein that includes a coiled-coil or a helix-loop-helix domain. Fusion genes with a break within intron 1 or 2 of $A B L 1$, such as BCR-ABL1, ZMIZ1-ABL1, EML1-ABL1 and $E T V 6-A B L 1$, carry transforming activity, while the NUP214-ABL1 requires amplification to be efficient [2].

\footnotetext{
* Correspondence: e.nacheva@ucl.ac.uk

'Leukaemia Cytogenetics, Academic Haematology, UCL Medical School, Royal Free Campus, Rowland Hill Street, London NW3 2PF, UK

${ }^{3}$ Leukaemia Cytogenetics, Royal Free NHS Foundation Trust, Pond Street, London NW3 2QG, UK

Full list of author information is available at the end of the article
}

The ETV6-ABL1 fusion was reported for the first time in a 22-month-old girl with ALL by Papadopoulos et al. in 1995 [3] and to date, this fusion gene has been reported in 28 cases of haematological malignancy [4-6]. Common characteristics of the ETV6-ABL1 translocation appears to be eosinophilia, seen in 16 out of the 21 patients for which data was available, a 2:1 male predominance and seen in patients with ages varying between 8 months and 81 years. The ETV6-ABL1 fusion is seen in a wide range of haematological malignancies: 5 patients had AML, 10 ALL and 3 with an MPN while the remaining 11 were described as having $\mathrm{Ph}$ negative CML, of which 3 presented in a blast crisis, summarised in Table 1 [3,4,7-24].

The structure of the ETV6-ABL1 oncoprotein is similar to that of BCR-ABL1, as evidenced by the fact that both fusion products lead to activation of the non-receptor tyrosine kinase ABL1 with initiation of similar downstream pathways effecting cellular survival, growth rate and independence as well as transforming capacity [25].

The existence of two different transcripts, type $\mathrm{A}$ and $B$, is evidence for alternative splicing. Type A transcript includes the first four exons of ETV6, fused to exon 2 of 
Table 1 Summary of published data for patients with etv6/abl1 fusion gene

\begin{tabular}{|c|c|c|c|c|c|c|c|c|c|c|c|c|}
\hline No & $\mathrm{Dg}$ & Sex & Age & TKI & Outcome & Eosinophilia & $\begin{array}{l}\text { Transcript } \\
\text { type }\end{array}$ & G banding & FISH/ETV6 & FISH/ABL1 & $\begin{array}{l}\text { Genome } \\
\text { features }\end{array}$ & Reference \\
\hline 1 & ALL & $\mathrm{F}$ & $22 \mathrm{mo}$ & No & Died & & A & na & na & na & na & Papadopoulos et al, 1995 Cancer Research [3] \\
\hline 2 & AML-M6 & M & 81 & No & Died & & B & $\begin{array}{l}\mathrm{t}(9 ; 12 ; 14)(\mathrm{q} 34 ; \mathrm{p} 13 ; \mathrm{q} 22) / \\
\text { complex karyotype }\end{array}$ & na & na & na & Golub et al., 1996 Mol \& Cellular Biology [7] \\
\hline 3 & $\begin{array}{l}\mathrm{CML} \\
\text { atypical }\end{array}$ & na & 49 & No & Died & Yes & B & na & na & na & na & Brunel et al., 1995 Leukemia [8] \\
\hline 4 & $\mathrm{CML}$ & M & 32 & No & $C R(>3 Y)$ & Yes & B & $46, X Y, t(12 ; 14)(p 12 ; q 11-13)$ & 5'ETV6 on 9q34 & $\begin{array}{l}A B L 13^{\prime} / 5^{\prime} \text { on } \\
9 q 34\end{array}$ & na & Andreasson et al., 1997 Genes, Chrom \& Ca [9] \\
\hline 5 & $C M L$ & M & 59 & No & Died & Yes & A & $\begin{array}{l}46, X Y, \text { del }(6)(p 21), ? t(9 ; 12) \\
(q 34 ; p 12)\end{array}$ & 5'ETV6 on 9q34 & $\begin{array}{l}A B L 13^{\prime} / 5^{\prime} \text { on } \\
9 q 34\end{array}$ & na & Van Limbergen et al., 2001 Genes, Chrom \& Ca [10] \\
\hline 6 & T/ALL & M & 4 & No & Died & Yes & $A, B$ & $47, X X Y c$,del(6)(q15q23) & 5'ETV6 on 9q34 & $\begin{array}{l}A B L 13^{\prime} / 5^{\prime} \text { on } \\
9 q 34\end{array}$ & na & Van Limbergen et al., 2001 Genes, Chrom \& Ca [10] \\
\hline 7 & $\begin{array}{l}\text { AML-M6/ } \\
\text { CML/MBC }\end{array}$ & M & 38 & Yes & Died & na & $A, B$ & $46, X Y$ & na & $3^{\prime} A B L 1$ on $12 p$ & $\begin{array}{l}\text { karyotype } \\
\text { evolution }\end{array}$ & O'Brien et al., 2002 Blood [11] \\
\hline 8 & CML & M & 53 & No & $C R(>6 Y)$ & Yes & $A, B$ & $46, X Y$ & na & $\begin{array}{l}A B L 13^{\prime} / 5^{\prime} \text { on } \\
9 q 34\end{array}$ & na & Lin et al., 2002 Leukemia [12] \\
\hline 9 & CML & $\mathrm{F}$ & 44 & Yes & $C R(>6 M)$ & Yes & & $46, X X, t(9 ; 12)(q 34 ; p 13)$ & $\begin{array}{l}5^{\prime}-3^{\prime} \text { ETV6 on } \\
9 q 34\end{array}$ & $\begin{array}{l}A B L 13^{\prime} / 5^{\prime} \text { on } \\
9 q 34\end{array}$ & na & Keung et al., 2002 Ca Gen \&Cytogen [13] \\
\hline 10 & AML-M1 & M & 29 & No & $\begin{array}{l}\mathrm{CR}(>20 \mathrm{M} \\
\text { post SCT) }\end{array}$ & Yes & A & $46, X Y, t(8 ; 12)(p 21 ; p 13)$ & 5'ETV6 on 8p21 & 3'ABL1 on 8p21 & na & La Starza et al., 2002 Haematologica [14] \\
\hline 11 & $\begin{array}{l}\text { AML-M1 } \\
\text { post RAEB }\end{array}$ & M & 48 & No & Died & Yes & B & $46, X Y, t(9 ; 12)(q 34 ; p 13)$ & na & $3^{\prime} A B L 1$ on $12 p$ & $\begin{array}{l}\text { karyotype } \\
\text { evolution }\end{array}$ & La Starza et al., 2002 Haematologica [14] \\
\hline 12 & CML-MBC & M & 36 & Yes & Died & Yes & B & $45, X Y-7, t(9 ; 12)(q 34 ; q 13)$ & na & $3^{\prime} A B L 1$ on $12 p$ & $\begin{array}{l}\text { karyotype } \\
\text { evolution }\end{array}$ & Barbouti et al., 2003 Br J Haematol [15] \\
\hline 13 & CML-LBC & M & 72 & Yes & $C R(>12 M)$ & na & B & $\begin{array}{l}46, X Y, t(12 ; 17) \\
(p 11.2 ; p 11.2)\end{array}$ & 5'ETV6 on $17 p$ & $3^{\prime} A B L 1$ on $17 p$ & & Tirado et al., 2005 Ca Gen \& Cytogen [16] \\
\hline 14 & CMPN & $\mathrm{F}$ & 65 & No & Died & Yes & $A, B$ & $46, X X, t(5 ; 9)(q 13 ; q 34)$ & na & $3^{\prime} A B L 1$ on $12 p$ & $\begin{array}{l}\text { karyotype } \\
\text { evolution }\end{array}$ & Meyer-Monard et al., 2005 Leukemia [17] \\
\hline 15 & CMPN & M & 57 & No & $C R(>15 Y)$ & Yes & na & $46, X Y$ & na & $3^{\prime} A B L 1$ on $12 p$ & na & Mozziconacci et al., 2007 Amer J of Haematol [18] \\
\hline 16 & ALL & M & 30 & & Died & & $A, B$ & $\begin{array}{l}45, X Y, \text { del(1)(q42),-9,-13, } \\
\operatorname{add}(16)(\mathrm{p} 1 ? 3),+ \text { mar }\end{array}$ & na & $3^{\prime} A B L 1$ on $12 p$ & p16 loss & Baeumler et al., 2008 Ca Gen \& Cytogen [19] \\
\hline 17 & CML & $\mathrm{F}$ & 24 & Yes & $C R(>7 M)$ & Yes & A & $46, X X$ & 5'ETV6 on 9q34 & $\begin{array}{l}A B L 13^{\prime} / 5^{\prime} \text { on } \\
9 q 34\end{array}$ & $\begin{array}{l}\text { loss ASS-ABL } \\
1 \text { exon1 }\end{array}$ & Kawamata et al., 2008 Genes,Chrom \& Ca [20] \\
\hline 18 & CMPN & $\mathrm{F}$ & 61 & Yes & $C R(>3 Y)$ & Yes & na & $46, X X$ & 5'-3'ETV6 on 12p & $3^{\prime} A B L 1$ on $12 p$ & na & Nand et al., 2009 Leuk Research [21] \\
\hline 19 & $\begin{array}{l}\mathrm{CML} \\
\text { atypical }\end{array}$ & M & 79 & Yes & Died & Yes & na & $46, X Y$ & 5'-3'ETV6 on 12p & $3^{\prime} A B L 1$ on $12 p$ & na & Kelly et al., 2009 Ca Gen \&Cytogen [22] \\
\hline 20 & ALL & $\mathrm{F}$ & 33 & & Died & No & $A, B$ & $46, X Y, \operatorname{der}(1) t(1 ; ?)$ & na & normal & p16/p15 loss & Zuna et al., 2010 Genes,Chrom \& Ca [4] \\
\hline 21 & ALL & M & 5 & No & $C R(>24 M)$ & Yes & $A, B$ & $46, X Y$ & na & $3^{\prime} A B L 1$ on $12 p$ & p16/p15 loss & Zuna et al., 2010 Genes,Chrom \&Ca [4] \\
\hline 22 & ALL & M & $8 \mathrm{mo}$ & Yes & Died & No & $A, B$ & $\begin{array}{l}46, X X, t(8 ; 9 ; 12) \\
(p 12 ; q 34 ; p 13)\end{array}$ & na & $3^{\prime} A B L 1$ on $12 p$ & na & Zuna et al., 2010 Genes,Chrom \& Ca [4] \\
\hline
\end{tabular}


Table 1 Summary of published data for patients with etv6/abl1 fusion gene (Continued)

\begin{tabular}{|c|c|c|c|c|c|c|c|c|c|c|c|c|}
\hline 23 & ALL & $\mathrm{F}$ & 8 & Yes & $C R(>10 M)$ & na & $A, B$ & $46 . X X$ & na & $3^{\prime} A B L 1$ on $12 p$ ? & na & Malone A et al., 2010 Br J Haematol [6] \\
\hline 24 & $C M L$ & M & 36 & Yes & $C R(>5 Y)$ & No & & $46, X Y, t(9 ; 12)(q 34 ; p 13)$ & na & $3^{\prime} A B L 1$ on $12 p$ & $\begin{array}{l}\text { normal UTX, } \\
\text { ASXL1, EZH2, } \\
\text { TET2 \& IDH1/2 }\end{array}$ & Perna et al., 2011 Haematologica [24] \\
\hline 25 & T/ALL & na & na & na & na & na & na & na & na & na & na & Zhou et al., 2012 Annual Haematology [5] \\
\hline 26 & T/ALL & na & na & na & na & na & na & na & na & na & na & Zhou et al., 2012 Annual Haematology [5] \\
\hline 27 & AML & M & 52 & No & Died & Yes & B & $46, X Y[20]$ & 5'-3'ETV6 on 12p & 3'ABL1 on $12 p$ & $\begin{array}{l}\text { normal FLT3, } \\
\text { cKit \& NPM1 }\end{array}$ & Park J et al., 2013 Acta Haematologica [23] \\
\hline 28 & B/ALL & $\mathrm{F}$ & 25 & No & Died & No & $A, B$ & $\begin{array}{l}\text { 46,XX,del(9)(p22), } \\
\operatorname{der}(10) t(9 ; 10)(q 22 ; p 15)\end{array}$ & 5'-3'ETV6 on 12p & $3^{\prime} A B L 1$ on $12 p$ & na & Park J et al., 2013 Acta Haematologica [23] \\
\hline 29 & CML & $\mathrm{F}$ & 52 & Yes & $C R>12 M$ & Yes & $A, B$ & $46, X X, t(9 ; 12)(q 34 ; p 13)$ & 5'ETV6 on $9 q 34$ & $\begin{array}{l}\text { ABL1 } 3^{\prime} / 5^{\prime} \text { on } \\
9 q 34\end{array}$ & 37 CNAs & Current study \\
\hline
\end{tabular}

Abbreviations: ALL Acute lymphoblastic leukemia, $A M L$ Acute myeloid leukemia, $C M L$ Chronic myeloid leukemia, MPN Myeloproliferative disease, $M B C$ Myeloid blast crisis, $L B C$ Lymphoid blast crisis, $F$ Female, $M$ male, $C R$ Cytogenetic remission, Na not available, CNAs Copy number aberrations. 
$A B L 1$, while type B includes exons 1 to 5 of ETV6 fused to $A B L 1$ exon 2 . The difference between the two transcripts at protein level is the presence or absence of a direct binding site for the SH2 domain of the GRB2. Million et al [26] showed that the GRB2 binding site in the ETV6-ABL1 product has several functions - from activation of the GAB2, PI3-kinase, and ERK-MAPK pathways to transformation of fibroblasts and B-lymphoid cells all of which are required for efficient induction of CML-like MPN. Furthermore, they demonstrated that the absence of ETV6 exon 5 leads to a slightly lower tyrosine kinase activity of the type A ETV6-ABL1 protein, although both kinases are as catalytically active as is the BCR-ABL1 product.

Since the ETV6 and $A B L 1$ genes have an opposite orientation to the chromosome centromere, the formation of a fusion requires at least three chromosomal breaks to be generated [2]. This could be the reason for the well-documented low incidence of ETV6-ABL1 fusion cases. Furthermore little is known regarding the effect of treatment with tyrosine kinase inhibitors on ETV6-ABL1 fusion positive haematological conditions.

Here we report a female patient, who presented with Philadelphia negative CML and $\mathrm{t}(9 ; 12)(\mathrm{q} 34 ; \mathrm{p} 13)$ as a sole bone marrow karyotype abnormality leading to ETV6$A B L 1$ fusion formation. Located on $\operatorname{der}(9) \mathrm{t}(9 ; 12)$, this fusion oncogene is shown to result from multiple events within a $5.6 \mathrm{Mb}$ region at $9 \mathrm{q} 34.12-\mathrm{q} 34.3$, which escapes detection by commercial $B C R-A B L 1$ FISH probes. Importantly, full cytogenetic and molecular remission was achieved only after second generation TKI treatment thus associating the ETV6-ABL1 fusion with TKI resistance.

\section{Case report}

In August 2011 a 46-year-old female presented with fatigue, a leucocytosis and thrombocytosis. Blood film examination was suggestive for CML with a neutrophilia, myelocyte peak, basophilia and also of note a eosinophilia of $2.5 \times 10^{9} / 1$. The aspirate morphology reported myeloid hyperplasia with reduced erythropoiesis, and increased eosinophilic and basophilic precursors. Histopathology reported a myeloproliferative neoplasm suggestive for CML chronic phase, with a markedly hypercellular bone marrow and myeloid hyperplasia with a left shift and loss of normal architecture. Erythroid activity was markedly reduced - only scattered CD71 positive cells were present. CD34 and CD117 show less than 5\% blasts. G-banding identified a balanced $\mathrm{t}(9 ; 12)(\mathrm{q} 34 ; \mathrm{p} 13)$ in $10 / 10$ metaphases and interphase FISH was positive in $92 \%$ of cells analysed. RT-PCR revealed the presence of ETV6-ABL1 fusion mRNA, while BCR-ABL1 was not detected. Such cases are not adequately covered by the WHO classification of myeloproliferative disorders and could be categorized as a ? CML variant.
Imatinib therapy achieved a complete haematological response (CHR) after 4 weeks and at 3 months, interphase FISH on the peripheral blood was positive in 37/ 200 cell $(18.5 \%)$. At 5 months thrombocytosis had recurred with the reappearance of a mild neutrophilia, basophilia and eosinophilia at 6 months. FISH analysis was positive in both interphase (50/200) and metaphase (6/ 20) cells and residual disease was confirmed by nested RT-PCR. She was switched to nilotinib, once again achieving a CHR after 4 weeks, and a complete cytogenetic response (CCyR) at 3 months. Major molecular response (MMR) was also achieved and in the subsequent specimens taken at 10, 12 and 18 months, ETV6-ABL1 mRNA was no longer detectable with nested RT-PCR. Both CCyR and MMR are sustained to date 22 months from diagnosis.

\section{Methods}

\section{(i) Cell Culture and chromosome studies}

Bone marrow (BM) and peripheral blood (PB) cell samples were cultured in RPMI medium following routine protocols as previously described [11]. High-resolution chromosome banding analysis was carried out and ISCN 2013 nomenclature was used to describe chromosome abnormalities [18].

\section{(ii) FISH and molecular cytogenetic analysis}

Fluorescence in situ hybridization (FISH) investigations were performed using commercially available $B C R-A B L 1$ probes (dual fusion probe, Vysis, USA) and ETV6 (breakapart probe Vysis, USA). Chromosome mapping of the $9 \mathrm{q} 34$ regions was carried out with a range of BAC clones (BACPAC Resources, USA). For disease monitoring a double fusion dual colour FISH probe was made with BAC clones covering the regions of $A B L 1$ (RP11-57C19 and RP11-83 J21), ETV6 (RP11-356 K6, RP11-418C2 and RP11-639O1) and NOTCH1 (RP11-707O3 and RP11-678D10) genes.

\section{(iii) RT-PCR}

Total RNA was extracted from the cell culture using Trizol reagent (Life Technologies, USA). Purified RNA was reverse transcribed, quality controlled and tested for $B C R$ $A B L 1$ as described previously [27] ETV6- $A B L 1$ was amplified in pretreatment samples by single step PCR using primers Tel3F2 (5'-CGCTATCGATCTCCTCATTCA-3') and CA3-b: (5'-ACACCATTCCCCATTGTGAT-3'). Two products were amplified, corresponding to a fusion ETV6 exon 4 to $A B L 1$ exon 2 and ETV6 exon 5 to $A B L 1$ exon 2. Remission samples were tested by nested PCR using primers TEL3F: (5'-CTGCTGACCAAAGAGGACTT-3') and CA3-: (5'-TGTTGACTGGCGTGATGTAGTTGC TTGG-3') in the first step and Tel32F2 + CA3-b in the 
second step. Dilution of pretreatment cDNA into negative control DNA indicated a sensitivity of detection of $10^{-4}$.

\section{(iv) Array Comparative Genomic Hybridisation (aCGH)}

Array $\mathrm{CGH}$ analysis was performed with a high-density customised $400 \mathrm{~K}$ oligonucleotide platform enriched with probes covering the coding regions of oncogenes (ID 027193, Agilent technologies, USA) following the manufacturer's protocol. In brief, $1500 \mathrm{ng}$ genomic test DNA was hybridised against a reference of a pooled DNA samples collected from PBMC of $6-8$ disease free individuals (Promega, UK). We used Genomic Workbench v.6 (Agilent technologies, USA) for data analysis as previously [28].

\section{Results}

(i) Philadelphia chromosome and BCR/ABL1 fusion are absent

$\mathrm{G}$ banding analysis of bone marrow cultures found both homologues of chromosome 22 intact, but identified a translocation of the long arm of chromosome 9 due to $t$ (9;12)(q34;p13) (Figure 1a). FISH analysis using a dual fusion, dual colour $B C R-A B L 1$ probe (Vysis) confirmed the absence of a fusion gene and hence the Philadelphia chromosome. However, some $21 \%$ of the interphase BM cells were found to harbour a third, albeit significantly smaller, $A B L 1$ signal found to be absent from the metaphases. The $A B L 1$ part of the D-FISH probe is $650 \mathrm{~Kb}$ long and any break upstream of exon 2 would result in two different in size segments. The proximal fragment covering the $A S S-A B L 1$ exon 2 region is larger $(\sim 500$ $\mathrm{Kb})$ and will remain on $\operatorname{der}(9) \mathrm{t}(9 ; 12)$. However, the FISH signal from the smaller distal segment $(\sim 150 \mathrm{~Kb})$ encompassing $A B L 1$ exon 2 to 11 was not found on the $\operatorname{der}(12) t(9 ; 12)$ chromosome as expected, although detected in some of the interphase cells (Figure 1b).

\section{(ii) Formation of the ETV6-ABL fusion at der $(9) t(9 ; 12)$ (q34;p13)}

A commercial ETV6 break-apart probe (Vysis) yielded a split signal located on $\operatorname{der}(9) \mathrm{t}(9 ; 12)$ in all dividing and $92 \%$ of the interphase BM cells demonstrating the rearrangement (Figure 1c). RT-PCR using published primers identified both type $\mathrm{A}$ and $\mathrm{B}$ transcripts of the ETV6-ABL1 fusion thus confirming ABL1 involvement [10]. However, such transcripts are unlikely to be a direct result of the $\mathrm{t}(9 ; 12)(\mathrm{q} 34 ; \mathrm{p} 13)$ because of the different orientation of the ETV6 and ABL1 genes. Furthermore, extensive research has already shown $[4,10]$ that the formation of a functional ETV6-ABL1 fusion gene requires

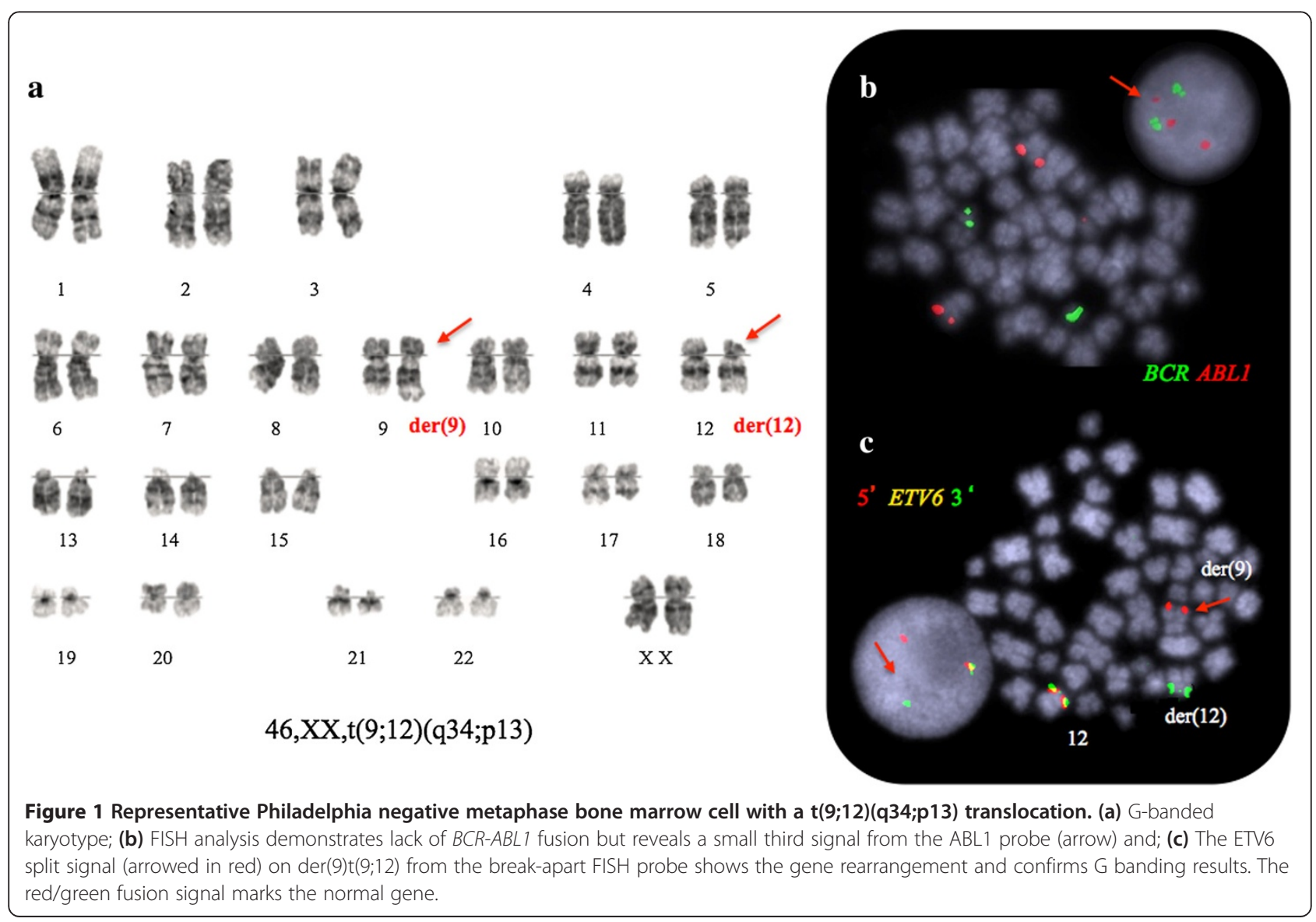


additional genome aberrations. Our failure to detect $A B L 1$ signals on the $\operatorname{der}(12) t(9 ; 12)$ in metaphase cells prompted us to search the 9q34 region by FISH 'walking' for multiple events that could facilitate the formation of the ETV6-ABL1 fusion (Figure 2). We detected a single break within 12p13 region and translocation of the $5^{\prime}$ part of the ETV6 gene (exon 1-5) some $40 \mathrm{~Kb}$ distal of the NOTCH1 gene (Figure 1c). This was shown by the presence of the BAC RP11-707O3 on $\operatorname{der}(9) \mathrm{t}(9 ; 12)$, while the distally located RP11-678D10 is moved to der(12)t $(9 ; 12)$. This FISH signal pattern suggests that ETV6 exons 1 - 5 sequences are located distally to $A B L 1$ (Figure 2, Additional files $1 \& 2$ ). Indeed the $A B L 1$ gene appears unaffected since FISH analysis of dividing cells shows both BAC clones that encompass the entire gene (i.e. RP1157C19 and RP11-83 J21) within the 9q34 region of der $(9) \mathrm{t}(9 ; 12)$. In contrast, FISH using either custom 9q34 $\mathrm{BAC}$ clones or commercial $B C R-A B L 1$ probes on interphase cells where the chromatin is less condensed allowing the discrimination of closely spaced DNA probes, revealed a third $A B L 1$ signal indicating breakage. The application of a cocktail of BAC clones in a three colour FISH experiment covering all relevant breakpoints in $12 \mathrm{p} 13,9 \mathrm{q} 34.12$ and $9 \mathrm{q} 34.3$, showed that in interphase cells the ETV6-ABL1 fusion is a considerable distance away from the proximal part of $A B L 1$ (exon 1b-2) and the neighbouring NOTCH1 gene (Figure 3, arrows), while in metaphase cells their discrimination is impossible. The ETV6-ABL1 fusion (both type $\mathrm{A}$ and type $\mathrm{B}$ transcripts) was confirmed by the RT-PCR and shown to occur after the break in the exon 1a-2 region of $A B L 1$ and exon 5 of ETV6 as expected. Whole genome scanning using oligonucleotide arrays revealed a total of 37 cryptic copy number aberrations (CNAs), mostly (24/37) gains (Additional file 3$)$. A cluster of CNAs was found within 9q33-qter including extra copy of the DAB2IP (a tumour suppressor gene with a recognised role in breast and prostate cancer) and within the regions flanking NOTCH1. A cryptic $140 \mathrm{bp}$ loss at chr12: $12,045,340-12,045,484$ was found at the breakpoint in the ETV6 gene (arrowed in Additional file 3). Other affected genome sites include the TNK2 gene at

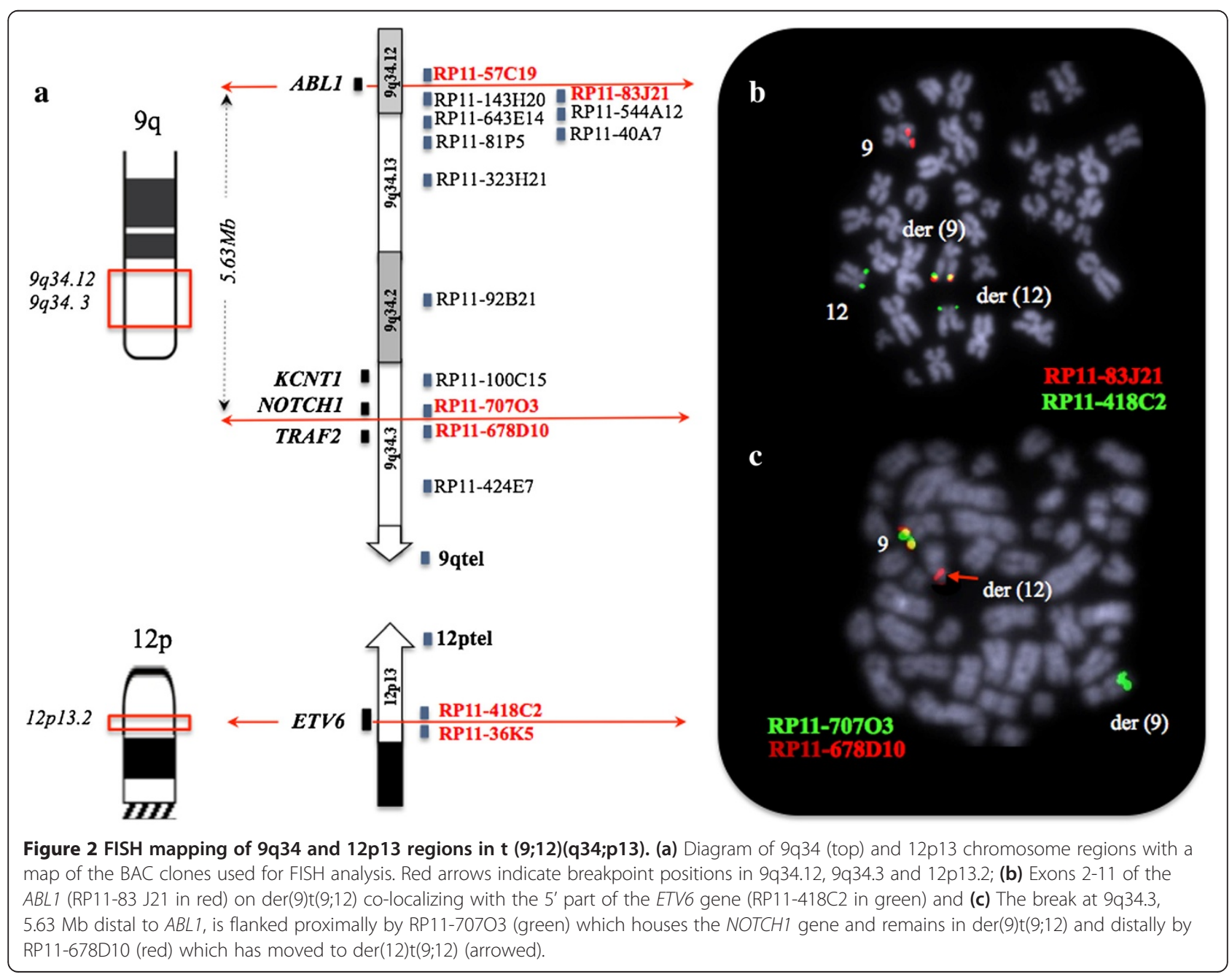


3q29, $3 \mathrm{Mb}$ gain at $8 \mathrm{q} 24.3$ that involves TOP1MT and $M A P K 15$ genes among others and extra copies of the $M L L$ gene at $11 \mathrm{q} 23$ as well as $M L L T 1$ at 19p13. Among the loci found deleted are transcription co-activator gene $C R E B B P$ at $16 \mathrm{p} 13.3$ and $C B F b$ at $16 \mathrm{q} 22$ (Additional file 3). It is noteworthy that only 2 of the 37 CNAs in this molecular karyotype are reported polymorphic imbalances, the rest represent cryptic secondary changes indicative of genome instability.

\section{Discussion}

ETV6 is one of the six genes known to form fusion chimeric transcripts with $A B L 1$. As a rule, the fusion gene results from joining the 3'sequences of $A B L 1$ with the 5 ' end of the partner genes. While most of these fusion genes are associated with a specific type of leukaemia, $B C R-A B L 1$ and ETV6-ABL1 are found in a wide spectrum of clinically and morphologically different malignant blood conditions [2]. In spite of their heterogeneity these conditions are likely to share a common progenitor cell, the pluripotent stem cell, since both chimeric genes activate similar transduction pathways with similar transforming activity [29].

The ETV6-ABL1 fusion gene is a truly rare event. So far there are 29 cases including the present study published after the first report in 1995 by Papadopoulos et al. (summarised in Table 1). The rarity of this fusion is due to the opposite transcriptional orientation of the two genes relative to the centromeres, which would require at least two events to form an in-frame fusion transcript. It is therefore not a surprise that the chromosome rearrangement producing the fusion gene often remains hidden. Perhaps the ETV6-ABL1 fusion is not as rare as the literature suggests since there are no satisfactory commercial FISH probes available for the detection of the ETV6-ABL1 fusion. In dividing cells with $\mathrm{t}(9 ; 12)$ (q34;p13), the dual colour/dual probe $B C R /$ $A B L 1$ set (D-FISH) should indicate an $A B L 1$ rearrangement by producing a third $A B L$ signal on $\operatorname{der}(12)$ while $B C R$ remains intact (Figure $1 \mathrm{~b}$ ). Unfortunately this abnormal signal pattern was not seen in metaphase cells in nearly a third of cases (27\%) where both parts of the rearranged $A B L 1$ remain within the 9q34/qter (Table 1). The situation is worse in interphase cells where the third signal may remain unaccounted for due to its small size as illustrated in our case and seen in a further 6 reports with ETV6-ABL1 fusion (Table 1). Analysts using widely available BCR-ABL1 commercial assays on interphase cells may regard the disproportionately small third signal from the $A B L 1$ probe as 'noise'. In contrast, FISH with the ETV6 break-apart (BA) probe will produce a split (third) signal at the $\operatorname{der}(9)$ chromosome that is easy to detect in interphase cells of fusion carriers (see Figure 2c). Therefore FISH screening with ETV6 (BA) probe of samples suspected for CML but negative for $B C R-A B L 1$ rearrangement by FISH, provides a reliable way to reassess the 'rarity' of this fusion gene. Indeed two recent studies $[4,5]$ have indicated that the incidence of ETV6-ABL1 fusion transcript may well be around $1 \%$, thus confirming our concerns that the occurrence of this translocation in haematological diseases is underestimated.

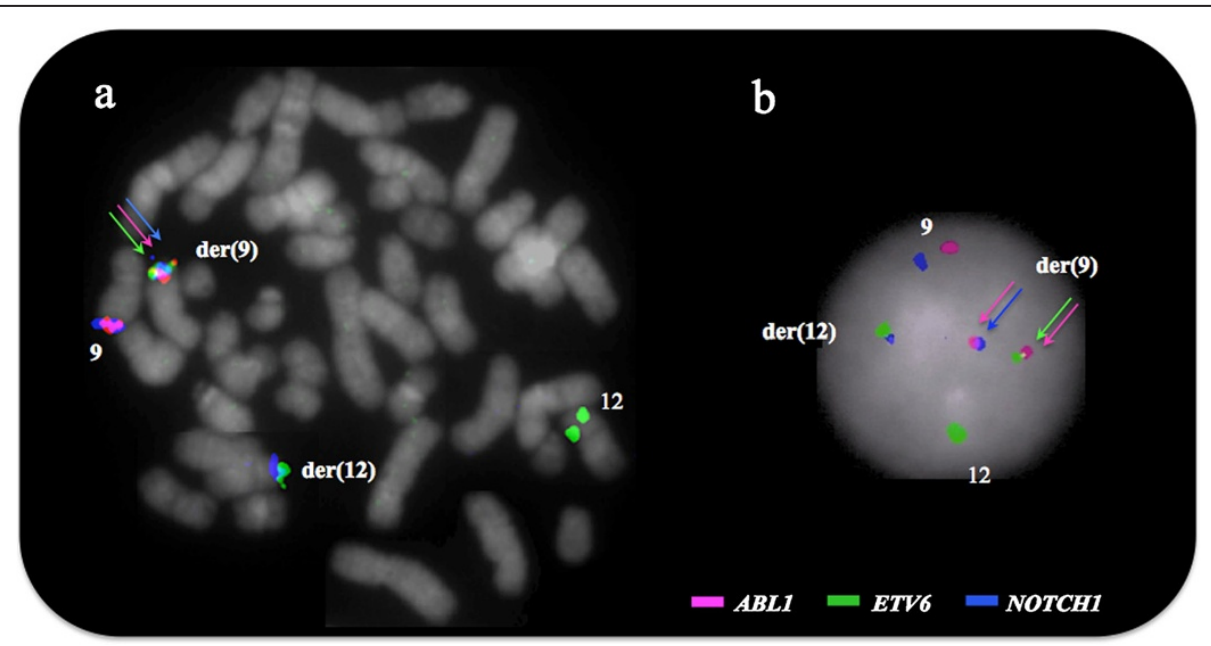

Figure 3 Representative cells with FISH signals showing the cryptic three way rearrangement of ABL1, NOTCH1 and ETV6 associated with $\mathbf{t}(\mathbf{9} ; 12)$ (q34;p13). BAC clones covering the regions of interest are as follows: ABL1 (RP11-83 J21 \& RP11-57C19, in red), NOTCH1 (RP1170703\&RP11-678D10, in blue) and ETV6 (RP11-418C2 \& RP11-36 K5, in green) (a) FISH signals from all three genes - ETV6, ABL1 and NOTCH1 cluster at der(9)t(9;12) in a metaphase cell (arrows) (b) in a non-dividing cell the ETV6 (exons 1-5)/ABL1 (exons 2-11) fusion(green/red arrow) is separated from the co-localized ABL1 (exons 1b-2) and NOTCH1 signals (red/blue arrows); while ABL1 and NOTCH1 signals ( 5.6 Mb apart) mark the normal 9 homologue and signals from ETV6 (green) and RP11-678D10 (downstream of NOTCH1, blue) co-hybridize at der(12)t(9;12). 
There are few descriptions in the literature of in-frame fusion products involving genes with different orientations. As a rule, formation of these fusion genes is associated with more than one event and more than the two breaks that are necessary for a classical reciprocal translocation. For example, Van Limbergen and colleagues [10] suggested two alternative mechanism. Our findings support a complex model (see Figure 4) that incorporates some of the suggested changes and highlight the fact that the ETV6-ABL1 fusion resides on $\operatorname{der}(9) \mathrm{t}(9 ; 12)$ in nearly a third of the cases thus rendering FISH with $A B L 1$ probes unfit for purpose.

Million et al. [30] demonstrated a striking similarity between the ETV6-ABL1 and BCR-ABL1 induced leukaemia in mouse models, the only difference being the latency period. They found that the ETV6-ABL1 fusion protein is significantly more active compared to the p210 BCRABL1. Importantly, both fusion proteins were shown to have similar helix-loop-helix domains, which is fused to the kinase domain of $A B L 1$ and implicated in protein oligomerisation process [31]. Indeed ETV6-ABL1 positive patients respond to treatment with tyrosine kinase inhibitors (TKI) as expected. Kawamata et al., reported a favourable response to imatinib in chronic phase CML with normal karyotype and ETV6-ABL1 [20]. However, the inhibitory effect of imatinib was short lived and unable to induce a complete remission in two further CML cases $[13,15]$. Similarly, Nand et al., [21] reported an ETV6$A B L 1$ fusion positive patient with a myeloproliferative disorder who developed morphologic and cytogenetic relapse after 17 months on imatinib but achieved complete remission on a second second-generation TKI (nilotinib). After an initial haematological response to imatinib $400 \mathrm{mg}$ daily our patient, who presented with typical chronic phase CML and t(9;12)(q34;p13) as sole karyotype abnormality, progressed at 3 months; whereas nilotinib achieved a prompt CCyR, followed by an MMR 16 months after diagnosis, which is sustained to date. The mechanism of the imatinib resistance reported here and by others is still unexplained. Although the long-term response to second generation TKIs remains to be determined, their implementation as first line therapy in ETV6-ABL1 (+) disorders is well supported.

\section{Conclusion}

In summary, we highlight two main features of ETV6$A B L 1$ positive disorders: firstly, the diagnostic value of FISH with the ETV6 (BA) probe and secondly, while this chimeric oncogene is associated with poor long term

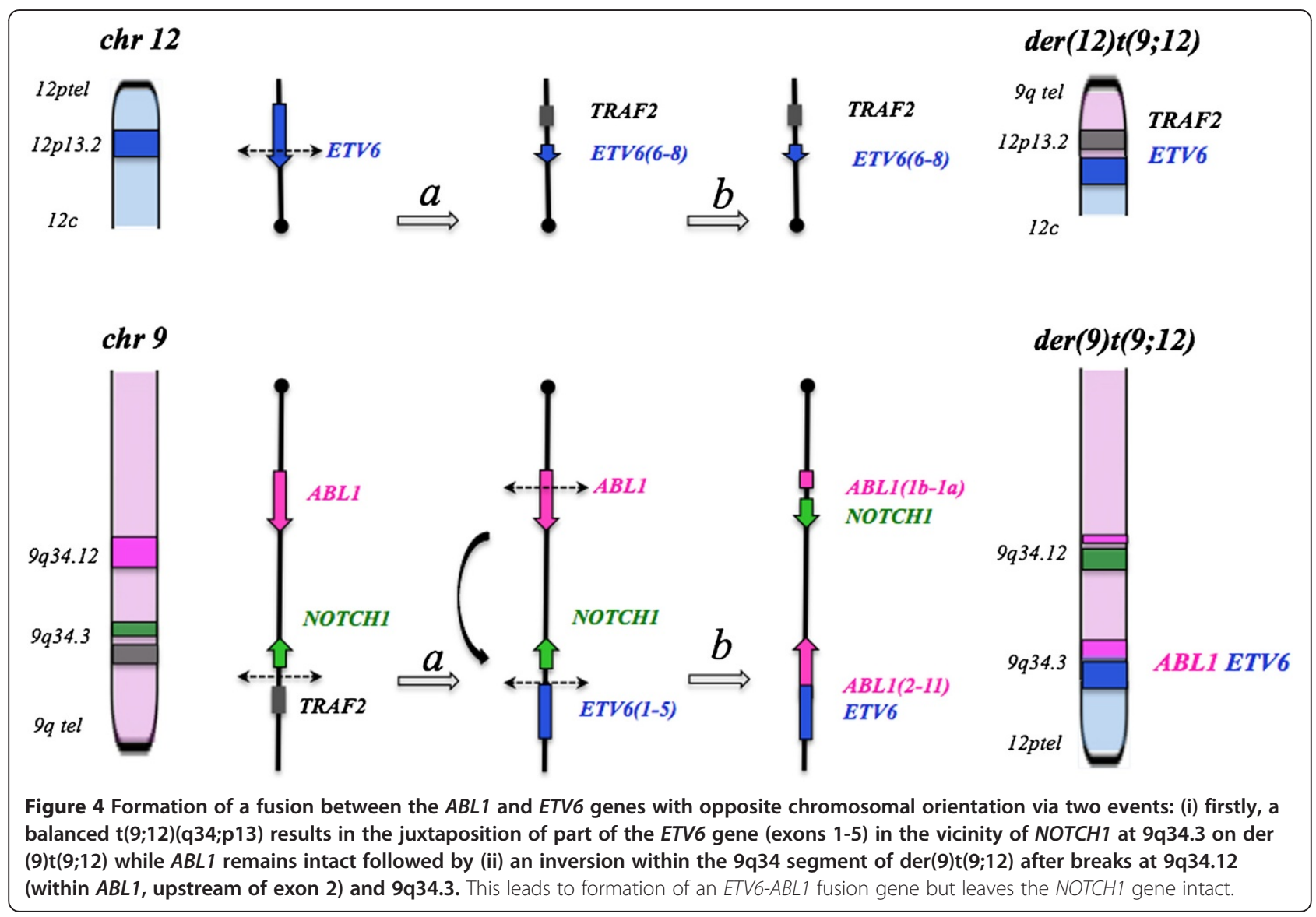


response to imatinib, our patient achieved a sustained response to nilotinib.

\section{Consent}

Written informed consent was obtained from the patient for publication of this Case Report and any accompanying images. A copy of the written consent is available for review by the Editor-in-Chief of this journal.

\section{Additional files}

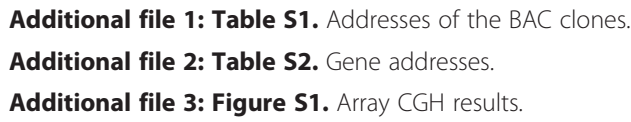

\section{Competing interests}

The authors declare that they have no competing interests.

\section{Authors' contributions}

KG carried out the molecular genetic studies, participated in the design of the study and drafted the manuscript. AV provided the clinical care and treatment and edited the manuscript. NC carried out the diagnostic RT-PCR analysis and edited the manuscript; JHR, DB, PK and FP carried out the diagnostic G-band and FISH analysis together with response to treatment. CG coordinated the array analysis and edited the manuscript. EN conceived, designed and coordinated the study. All authors read and approved the final manuscript.

\section{Author details}

'Leukaemia Cytogenetics, Academic Haematology, UCL Medical School, Royal Free Campus, Rowland Hill Street, London NW3 2PF, UK. ${ }^{2}$ Department of Haematology, Barnet and Chase Farm Hospitals NHS Trust, Barnet Hospital, Wellhouse Lane, Barnet, London, Hertforshire EN2 3DJ, UK. ${ }^{3}$ Leukaemia Cytogenetics, Royal Free NHS Foundation Trust, Pond Street, London NW3 2QG, UK. ${ }^{4}$ Faculty of Medicine, University of Southampton, Southampton, UK.

Received: 28 June 2013 Accepted: 20 August 2013 Published: 20 September 2013

\section{References}

1. Al-Achkar W: A chronic myeloid leukemia case with a unique variant Philadelphia translocation: $\mathrm{t}(9 ; 22 ; 21)(q 34 ; q 11 ; p 12)$. Oncol Lett 2012, 3(5):1027-1029. Epub 2012 Feb 28.

2. De-Braekeleer E, Douet-Guilbert N, Rowe D, Bown N, Morel F, Berthou C, Férec C, De-Braekeleer M: ABL1 fusion genes in hematological malignancies: a review. Eur J Haematol 2011, 86:361-371.

3. Papadopoulos P, Ridge SA, Boucher CA, Stocking C, Wiedemann LM: The novel activation of $A B L$ by fusion to an ets-related gene, TEL. Cancer Res 1995, 55:34-38.

4. Zuna J, Zaliova M, Muzikova K, Meyer C, Lizcova L, Zemanova Z, Brezinova J, Votava F, Marschalek R, Stary J, Trka J: Acute leukemias with ETV6/ABL1 (TEL/ABL) fusion: poor prognosis and prenatal origin. Genes Chromosomes Cancer 2010, 49:873-884.

5. Zhou M-H, Gao L, Jing Y, Xu Y-Y, Ding Y, Wang N, Wang W, Li M-Y, Han X-P, Sun J-Z, Wang L-L, Yu L: Detection of ETV6 gene rearrangements in adult acute lymphoblastic leukemia. Ann Hematol 2012, 91:1235-1243.

6. Malone A, Langabeer S, O'Marcaigh A, Storey L, Bacon CL, Smith OP: A doctor(s) dilemma: ETV6-ABL1 positive acute lymphoblastic leukaemia. Br J Haematol 2010, 151:101-102.

7. Golub TR, Goga A, Barker GF, Afar DE, McLaughlin J, Bohlander SK, Rowley $\mathrm{JD}$, Witte ON: Oligomerization of the ABL tyrosine kinase by the Ets protein TEL in human leukemia. Mol Cell Biol 1996, 16:4107-4116.

8. Brunel V, Sainty D, Costello R, Mozziconacci M-J, Simonetti J, Arnoulet C, Coignet L, Bouabdallah R, Gastaut JA, Gabert J: Translocation of BCR to chromosome 9 in a Philadelphia-negative chronic myeloid leukemia. Cancer Genet Cytogenet 1995, 85:82-84.
9. Andreasson P, Johansson B, Carlsson M, Jarlsfelt I, Fioretos T, Mitelman F, Höglund $\mathrm{M}: \mathrm{BCR} / \mathrm{ABL}$-negative chronic myeloid leukemia with ETV6/ABL fusion. Genes Chromosomes Cancer 1997, 20:299-304.

10. Van-Limbergen $H$, Beverloo HB, van-Drunen $E$, Janssens $A$, Hählen $K$, Poppe B, Van-Roy N, Marynen P, De-Paepe A, Slater R: Molecular cytogenetic and clinical findings in ETV6/ABL1positive leukemia. Genes Chromosomes Cancer 2001, 30:274-282.

11. O'Brien SG: Transient response to imatinib mesylate (STI571) in a patient with the ETV6-ABL t (9;12) translocation. Blood 2002, 99:3465-3467.

12. Lin H, Guo JQ, Andreeff M, Arlinghaus RB: Detection of dual TEL-ABL transcripts and a Tel-Abl protein containing phosphotyrosine in a chronic myeloid leukemia patient. Leukemia 2002, 16:294.

13. Keung YK, Beaty M, Steward W, Jackle B, Pettnati M: Chronic myelocytic leukemia with eosinophilia, $\mathrm{t}(9 ; 12)(\mathrm{q} 34 ; \mathrm{p} 13)$, and ETV6-ABL gene rearrangement: case report and review of the literature. Cancer Genet Cytogenet 2002, 138:139-142

14. La-Starza RR, Trubia MM, Testoni NN, Ottaviani EE, Belloni EE, Crescenzi BB, Martelli MM, Flandrin GG, Pelicci PGP, Mecucci CC: Clonal eosinophils are a morphologic hallmark of ETV6/ABL1 positive acute myeloid leukemia. Haematologica 2002, 87:789-794.

15. Barbouti A, Ahlgren T, Johansson B, Hoglund M, Lassen C, Turesson I, Mitelman F, Fioretos T: Clinical and genetic studies of ETV6/ABL1-positive chronic myeloid leukaemia in blast crisis treated with imatinib mesylate. Br J Haematol 2003, 122:85-93.

16. Tirado C, Sebastian S, Moore J, Gong J, Goodman B: Molecular and cytogenetic characterization of a novel rearrangement involving chromosomes 9, 12, and 17 resulting in ETV6 (TEL) and ABL fusion. Cancer Genet Cytogenet 2005, 157:74-77.

17. Meyer-Monard S, Mühlematter D, Streit A, Chase AJ, Gratwohl A, Cross NCP, Jotterand $\mathrm{M}$, Tichelli A: Broad molecular screening of an unclassifiable myeloproliferative disorder reveals an unexpected ETV6/ABL1 fusion transcript. Leukemia 2005, 19:1096-1099.

18. Mozziconacci M-J, Sainty D, Chabannon C: A fifteen-year cytogenetic remission following interferon treatment in a patient with an indolent ETV6-ABL positive myeloproliferative syndrome. Am J Hematol 2007 82:688-689.

19. Baeumler J, Szuhai K, Falkenburg JHF, van-Schie MLJ, Ottmann OG, Nijmeijer BA: Establishment and cytogenetic characterization of a human acute lymphoblastic leukemia cell line (ALL-VG) with ETV6/ABL1 rearrangement. Cancer Genet Cytogenet 2008, 185:37-42.

20. Kawamata N, Dashti A, Lu D, Miller B, Koeffler HP, Schreck R, Moore S, Ogawa S: Chronic phase of ETV6-ABL1 positive CML responds to imatinib. Genes Chromosomes Cancer 2008, 47:919-921.

21. Nand R, Bryke C, Kroft SH, Divgi A, Bredeson C, Atallah E: Myeloproliferative disorder with eosinophilia and ETV6-ABL gene rearrangement: Efficacy of second-generation tyrosine kinase inhibitors. Leuk Res 2009, 33:1144-1146.

22. Kelly JC, Shahbazi N, Scheerle J, Jahn J, Suchen S, Christacos NC, Mowrey PN, Witt $\mathrm{MH}$, Hostetter A, Meloni-Ehrig AM: Insertion (12;9)(p13;q34q34): a cryptic rearrangement involving $A B L 1 / E T V 6$ fusion in a patient with Philadelphianegative chronic myeloid leukemia. Cancer Genet Cytogenet 2009, 192:36-39.

23. Park J, Kim M, Lim J, Kim Y, Han K, Kim JS, Lee S, Kim H-J, Min WS: Variant of ETV6/ABL1 gene is associated with leukemia phenotype. Acta Haematol 2013, 129:78-82.

24. Perna F, Abdel-Wahab O, Jhanwar SC, Imada K, Nimer SD: ETV6-ABL1positive "chronic myeloid leukemia": clinical and molecular response to tyrosine kinase inhibition. Haematol 2011, 96:342-343.

25. Malinge S, Monni R, Bernard O, Penard-Lacronique $\mathrm{V}$ : Activation of the NF$\mathrm{KB}$ pathway by the leukemogenic TEL-Jak2 and TEL-Abl fusion proteins leads to the accumulation of antiapoptotic IAP proteins and involves IKKa. Oncogene 2006, 25:3589-3597.

26. Million RP, Harakawa N, Roumiantsev S, Varticovski L, Van-Etten RA: A Direct Binding Site for Grb2 Contributes to Transformation and Leukemogenesis by the Tel-Abl (ETV6-Abl) Tyrosine Kinase. Mol Cell Biol 2004, 24:4685-4695.

27. Cross NC, Melo JV, Feng L, Goldman JM: An Optimized Multiplex Polymerase Chain Reaction (PCR) for Detection of BCR-ABL Fusion mRNAs in Haematological Disorders. Leukemia 1994, 8:186-189.

28. Nacheva EP, Brazma D, Virgili A, Howard-Reeves J, Chanalaris A, Gancheva K, Apostolova M, Valgañon M, Mazzullo H, Grace C: Deletions of immunoglobulin heavy chain and $T$ cell receptor gene regions are 
uniquely associated with lymphoid blast transformation of chronic myeloid leukemia. BMC Genomics 2010, 11:41.

29. Okuda K: ARG tyrosine kinase activity is inhibited by STI571. Blood 2001 97:2440-2448

30. Million RP: The Tel-Abl (ETV6-Abl) tyrosine kinase, product of complex $(9 ; 12)$ translocations in human leukemia, induces distinct myeloproliferative disease in mice. Blood 2002, 99:4568-4577.

31. Hannemann JRJ, McManus DMD, Kabarowski JHJ, Wiedemann LML: Haemopoietic transformation by the TEL/ABL oncogene. $\mathrm{Br} J$ Haematol 1998, 102:475-485.

doi:10.1186/1755-8166-6-39

Cite this article as: Gancheva et al:: Myeloproliferative neoplasm with ETV6-ABL 1 fusion: a case report and literature review. Molecular Cytogenetics 2013 6:39.

\section{Submit your next manuscript to BioMed Central and take full advantage of:}

- Convenient online submission

- Thorough peer review

- No space constraints or color figure charges

- Immediate publication on acceptance

- Inclusion in PubMed, CAS, Scopus and Google Scholar

- Research which is freely available for redistribution 